\title{
Possible Case Report of Furosemide-Induced Psoriasis
}

\author{
Abstract \\ Purpose: After reviewing PubMed, drug-induced psoriasis \\ has been previously reported. This case is believed to be the first \\ furosemide-induced psoriasis reported and includes a summarization \\ of antihypertensive-induced psoriasis on some of the previously \\ published literature.
}

Summary: A 32-year-old African American female with hypertension secondary to edema was noted to have developed psoriasis 3.3 years after the initiation of furosemide $20 \mathrm{mg}$ orally once daily. She initially had a new-onset rash to hydrochlorothiazide $25 \mathrm{mg}$ orally once daily after 1 week prior to switching to furosemide. After presenting with her psoriatic-like skin lesions all throughout her body while on furosemide for 3.3 years, dermatologic biopsy confirmed the psoriasis diagnosis. After discontinuation of furosemide and initiation of topical and oral supportive medications, the patient's psoriasis resolved after 4 weeks. She was changed to lisinopril $10 \mathrm{mg}$ orally once daily then finally switched to losartan $50 \mathrm{mg}$ orally once daily with spironolactone $50 \mathrm{mg}$ orally twice daily.

Conclusion: Using the scale of Naranjo et al. it was determined that furosemide use was the possible cause of the patient's psoriasis. This report can contribute to the literature by describing another druginduced psoriasis and provide a possible first case report of furosemideinduced psoriasis.

\section{Introduction}

Psoriasis is a chronic, inflammatory condition, commonly affecting either the joints, skin, or both [1]. Plaque psoriasis is the most common type of psoriasis, affecting approximately $2 \%$ of Americans [1]. This type of psoriasis is defined as a dermatologic condition, causing well-defined, erythematosus plaques on hands, feet, and extremities [1]. Plaque psoriasis can be induced by certain medications, such as beta-blockers, lithium, indomethacin, and tetracycline $[2,3]$.

Furosemide is one of four high-ceiling or loop diuretics that has been available for nearly fifty years. Structurally, it retains similarities to the thiazide diuretic, hydrochlorothiazide (HCTZ), but would be better classified as an open-chain analogue. The thiazide ring within hydrochlorothiazide possesses a weakly acidic proton, which is required for activity. As an open-chain analogue, furosemide substitutes the acidic thiazide with a more acidic carboxylic acid (Figure 1). A furanylmethyl functional group is attached to the other

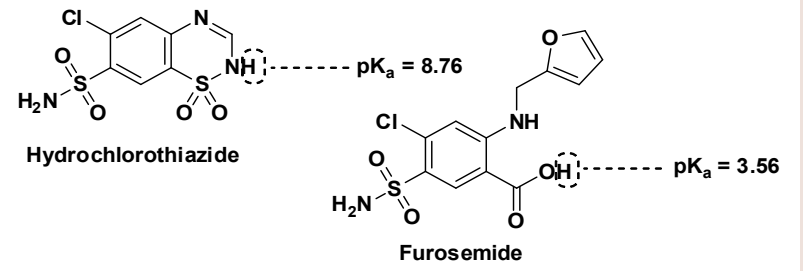

Figure 1: Structures of hydrochlorothiazide and furosemide with pka values.

\section{Journal of}

Pharmaceutics \& Pharmacology

\author{
Jennifer Clements ${ }^{1^{*}}$, Kristopher G. Virga ${ }^{2}$ and Aida \\ R. Bickley ${ }^{1}$
}

${ }^{\prime}$ Department of Pharmacy Practice, Presbyterian College School of Pharmacy, South Carolina, USA

${ }^{2}$ Department of Pharmaceutical Sciences, Presbyterian College School of Pharmacy, South Carolina, USA

\section{Address for Correspondence}

Jennifer Clements, Pharm.D, BCPS, CDE, BCACP, Department of Pharmacy Practice, Presbyterian College School of Pharmacy, $307 \mathrm{~N}$, Broad Street Clinton, South Carolina 29325, USA, Tel: 8649383870; E-mail: jclements@presby.edu

Submission: 13 October 2015
Accepted: 05 November 2015
Published: 10 November 2015

Copyright: (๑ 2015 Clements $\mathrm{J}$ et al. This is an open access article distributed under the Creative Commons Attribution License, which permits unrestricted use, distribution, and reproduction in any medium, provided the original work is properly cited.

Reviewed \& Approved by: Dr. Rutesh H. Dave, Associate Professor, Division of Pharmaceutical Sciences, Arnold and Marie Schwartz College of Pharmacy and Health sciences, Long Island University, USA

amine nitrogen. These structural differences alter the mechanistic binding activity, as well as serving to increase the overall saliuretic efficacy [4]. Furosemide has a saliuretic effect 8 to 10 times that of the thiazide diuretics, but with a much shorter half-life, whereas HCTZ acts by inhibiting the $\mathrm{Na}^{+} / \mathrm{Cl}^{-}$symporter located in the distal convoluted tubule. Furosemide acts by inhibiting the luminal $\mathrm{Na}^{+} /$ $\mathrm{K}^{+} / 2 \mathrm{Cl}^{-}$symporter in the thick ascending loop of henle. The oral absorption and bioavailability for furosemide ranges between 50 to $70 \%$ [5]. The half-life of furosemide ranges from 0.33 to 1.17 hours in healthy subjects, and from 4.9 to 9.7 hours in patients with advanced renal failure [5]. Although furosemide is generally considered to be safe and effective at normal therapeutic doses, it has been associated with a number of potential adverse effects attributable to idiosyncratic metabolism [6,7].

\section{Objective}

In clinical practice, furosemide is commonly used for symptomatic management of heart failure and blood pressure management. The effect of furosemide causing psoriasis has not been published in the literature. We summarize a possibly case report of furosemideinduced psoriasis. In addition, we conducted a PubMed search and reviewed literature regarding antihypertensive medications and psoriasis.

\section{Case Report}

The patient is a 32-year-old African American female, who became a new patient to the rural-health, family medicine clinic in August 2010. Family history included father and mother alive and well; the patient did not have a significant social history as she denied smoking any tobacco products and drinking alcohol. She did not 
Table 1: Timeline of events

\begin{tabular}{|c|c|c|c|}
\hline Visit & $\begin{array}{c}\text { Time Frame } \\
\text { since Initial } \\
\text { Visit }\end{array}$ & $\begin{array}{c}\text { Changes in } \\
\text { Medications }\end{array}$ & $\begin{array}{c}\text { Comments towards Case } \\
\text { Report }\end{array}$ \\
\hline 1 & 0 weeks & $\begin{array}{c}\text { Initiation of } \\
\text { hydrochlorothiazide }\end{array}$ & None \\
\hline 2 & 1 to 2 weeks & $\begin{array}{c}\text { Discontinuation of } \\
\text { hydrochlorothiazide } \\
\text { Initiation of furosemide }\end{array}$ & $\begin{array}{c}\text { Rash, itching reported with } \\
\text { hydrochlorothiazide }\end{array}$ \\
\hline 3 & 1 to 2 weeks & $\begin{array}{c}\text { Continuation of } \\
\text { furosemide }\end{array}$ & Rash resolved \\
\hline 4 & 40 months & $\begin{array}{c}\text { Discontinuation of } \\
\text { furosemide } \\
\text { Initiation of lisinopril }\end{array}$ & $\begin{array}{c}\text { Psoriasis-type reaction } \\
\text { reported and confirmed with } \\
\text { biopsy }\end{array}$ \\
\hline 5 & 4 weeks & $\begin{array}{c}\text { Discontinuation of } \\
\text { lisinopril } \\
\text { Initiation of losartan } \\
\text { and spironolactone }\end{array}$ & $\begin{array}{r}\text { Psoriasis-type reaction } \\
\text { resolved }\end{array}$ \\
\hline
\end{tabular}

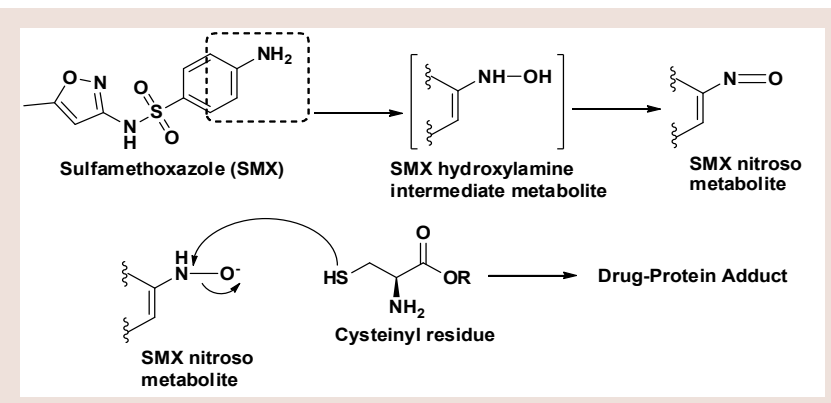

Figure 2: Sulfamethoxaole metabolism to protein-reactive metabolites.

have any insurance coverage. Table 1 summarizes the timeline of this possible case report.

At her initial primary care appointment with a nurse practitioner, the patient had no documentation for current or past medical history. She had a chief complaint of migraines and allergic rhinitis. In July 2011, the patient was seen due to complaints of edema in feet and ankles for 1 to 2 weeks. She denied consuming extra salt from dietary sources. At this visit, her height was not recorded, weight was $120 \mathrm{~kg}$ (266 lbs); her body mass index (BMI) $\mathrm{kg} / \mathrm{m}^{2}$ could not be calculated. Due to edema, the patient's blood pressure (BP) was $151 / 101 \mathrm{~mm}$ Hg; Therefore, HCTZ $25 \mathrm{mg}$ orally once daily was initiated with comprehensive metabolic panel (CMP), lipid panel, and thyroid stimulating hormone (TSH). One week later in July 2011, the patient contacted the clinic via telephone regarding HCTZ. She complained of new-onset rash and itching; therefore, she was scheduled to see the nurse practitioners within 3 days. At the face-to-face appointment, the patient had stopped HCTZ at the time of her telephone call. Vital signs were: weight $119.75 \mathrm{~kg}$ (264 lbs) and BP 158/102 mm Hg. The rash had completely resolved; there were no abnormalities of an allergic or anaphylactic reaction documented in the progress note. To replace HCTZ, the patient was initiated on furosemide $20 \mathrm{mg}$ orally once daily. To ensure tolerance with furosemide, the patient returned 11 days later with no complaints.

Since July 2011, the patient was seen periodically by the nurse practitioner for sinus infections, related to allergic rhinitis. The patient did receive refills of furosemide from July 2011 to November 2014 and adequate follow-up on CMP. In November 2014, the patient scheduled an appointment to discuss her antihypertensive medication as she had stopped furosemide one day ago. Upon presenting for the appointment, the patient explained she developed an extensive rash with furosemide. She was able to be seen by a dermatologist, who completed a biopsy and confirmed the diagnosis of psoriasis. The dermatologist prescribed triamcinolone spray $0.147 \mathrm{mg} / \mathrm{g}$ applied topically twice daily, prednisone 20 -day taper with $10 \mathrm{mg}$ tablets, and ketoconazole $200 \mathrm{mg}$ orally once daily. At the following primary care appointment, the patient's vital signs were height $154.94 \mathrm{~cm}$ (61 in), weight $105.51 \mathrm{~kg}$ (232.6 lbs) and BP 158/102 mm Hg. Her calculated BMI was $43.94 \mathrm{~kg} / \mathrm{m} 2$. The nurse practitioner documented severe psoriatic areas on trunk, arms, neck and face; peeling of skin between breasts; silvery scales; and papular area on lower extremities. The nurse practitioner documented reaction to furosemide in the patient's medical record. To replace furosemide, lisinopril $10 \mathrm{mg}$ orally once daily. In December 2014, the patient returned for a followup on reaction with furosemide. Dermatologic changes had resolved, but patient reported edema in feet and ankles. The antihypertensive regimen was modified as discontinuation of lisinopril and initiation of losartan $50 \mathrm{mg}$ orally once daily with spironolactone $50 \mathrm{mg}$ orally twice daily. Basic metabolic panel was obtained and no abnormalities were reported.

\section{Discussion}

No similar case report has been documented in the literature to date. This case report scored a 4 on the Naranjo et al. scale of causality, classifying the case report as "possible" of furosemideinduced psoriasis [8].

Structurally, furosemide contains a sulfonamide moiety attached to an aromatic ring. Furosemide, along with many other sulfonamidecontaining agents, has typically been considered contraindicated in patients with a documented sulfa allergy [9]. The mechanism behind sulfonamide allergenicity has become better understood in recent

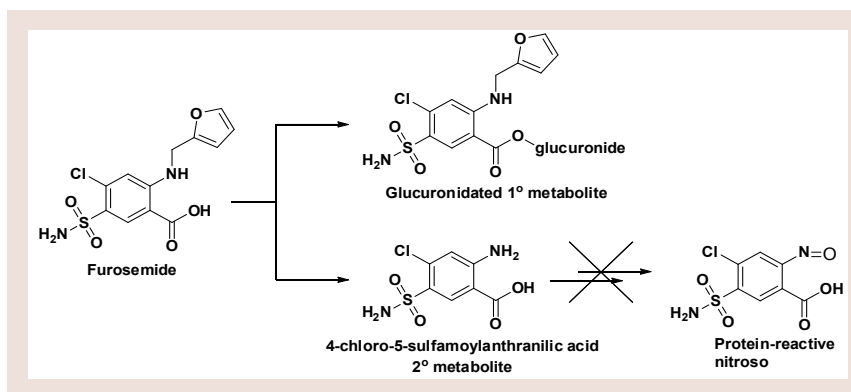

Figure 3: Furosemide primary and secondary metabolites.

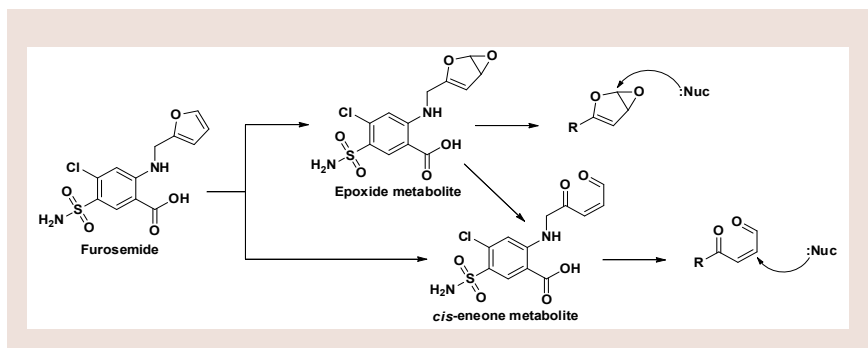

Figure 4: Furosemide protein-reactive metabolites. 
years with evidence supporting the aryl amine (aniline) para to the sulfonamide being responsible rather than the sulfonamide itself $[10,11]$. The aniline undergoes cytochrome P450-mediated oxidation to generate the pro-reactive hydroxylamine redox intermediate. This intermediate can undergo further oxidation to the nitroso species, which is a suitable electrophile capable of covalently modifying proteins at suitable nucleophilic sites such as sulfhydryl cysteines (Figure 2) [11]. The resulting reactive metabolite-protein adduct, or hapten, can lead to a number of negative effects, including cellular damage through stress, initiation of apoptosis, and/or an immunemediated response to the perceived foreign protein [12]. Because most non-antibiotic sulfonamides do not contain a para-aniline to the sulfonamide, it is unlikely that they will actually be cross-reactive in patients with a documented sulfa allergy.

Furosemide does in fact possess an aniline para to the sulfonamide, though the amine is substituted with the furanylmethyl at that position. It would be expected that the aniline could become unsubstituted through the process of $\mathrm{N}$-dealkylation to yield the 4-chloro-5-sulfamoylanthranilic acid metabolite (Figure 3). In fact, this metabolite was the first to be identified in the literature, though the glucuronide conjugate is now known to be the major human metabolite $[5,13,14]$. There have been no reports to date of adverse events associated with furosemide attributed to the formation of a reactive nitroso species similar to the sulfonamides. Furosemide is susceptible to idiosyncratic metabolism capable of producing a protein-reactive metabolite and is known to cause severe necrosis in mice at doses $\geq 300 \mathrm{mg} / \mathrm{kg}$; liver necrosis has not been reported in humans $[5,15,16]$. The reactive metabolite(s) appear to result from CYP 450-mediated oxidation of the furan ring in hepatic microsomes. Structurally, they are either an epoxide or a cis-enedione ( $\beta$-dicarbonyl), or perhaps a combination of the two [17]. Either of the metabolites is sufficiently electrophilic to react with cellular nucleophiles contained within proteins and DNA (Figure 4). It is reasonable to assume that certain combinations of drug-protein adduct formed through this reaction process are responsible for the various reports of furosemide adverse reactions.

Though the overall incidence rate for adverse reactions associated with furosemide is low, the described reactions are quite variable. The list of documented reactions includes; eczema, purpura, bullous pemphigoid, lichenoid drug eruptions, acute generalized exanthematous pustulosis (AGEP), Steven-Johnson's syndrome, and immune thrombocytopenia [7,18-20]. One case report of fatal autoimmune hemolytic anemia documented the presence of furosemide and tolmetin antibodies in the patient's serum [21]. However, the patient's case was too complex, involving an additional 19 medications, for the autoimmune hemolytic anemia to be positively attributed to the drug antibodies. A number of drugs are known to induce psoriasiform eruptions in patients with no previous history of psoriasis and to worsen existing cases [7]. Considering the known formation of protein-reactive metabolites from furosemide and the number of documented adverse effects involving dermal lesions, the potential for furosemide-induced psoriasis is not an inconsistent possibility.

In a United Kingdom population-based case-control study, Brauchli et al. investigated the association between antihypertensive agents and psoriasis [22]. The authors evaluated the first-time diagnosis of psoriasis among patients who had previous use of beta-blockers, angiotensin converting enzyme (ACE) inhibitors, angiotensin II receptor blockers, calcium channel blockers, diuretics, and clonidine. Cases were identified and matched with controls on age, sex, general practice, and years of history in the database. Cases were stratified based on number of prescriptions ( 1 to $4 ; 5$ to 1 ; and above 20) for previous or current use of the antihypertensive medications. In this study, baseline characteristics were similar except smoking and alcohol intake was more prevalent among cases. Approximately $14 \%$ of patients had hypertension, but control of this condition was not addressed by the authors. At baseline, individuals with BMI 25 to $29.9 \mathrm{~kg} / \mathrm{m}^{2}$ (OR 1.14 (1.09-1.19)) or 30 to $60 \mathrm{~kg} / \mathrm{m}^{2}$ (OR 1.38 (1.31-1.45)) had a higher risk of psoriasis. The trial did not support an association between antihypertensive agents and first-time diagnosis of psoriasis. However, the current use of diuretics had higher adjusted odds ratio (OR) for any prescription use (1 to 4 prescriptions: OR 1.17 (1.08-1.27); 5 to 19 prescriptions: OR 1.16 (1.03-1.32); above 20 prescriptions: OR 1.27 (1.09-1.48). In relationship to this case report, the case-control study did not list the names or therapeutic class of diuretics evaluated among the cases [22]. This study is difficult to extrapolate back to our reported case of possible furosemide-induced psoriasis. However, the patient had a BMI of $43.94 \mathrm{~kg} / \mathrm{m}^{2}$ in November 2014, which may have been a contributing factor towards the risk of psoriasis. In a prospective cohort study, $\mathrm{Wu}$ et al. investigated the association of hypertension and antihypertensive medications with physician-diagnosed psoriasis [23]. From this study, a patient with hypertension treated with medication can have a higher risk of psoriasis (OR 1.31 (1.10-1.55). For our patient, her diagnosis of hypertension and treatment may have increased her risk of psoriasis induction. It is unknown if the risk of psoriasis is affected with control of hypertension. In the study by $\mathrm{Wu}$ et al. only thiazide diuretics were investigated, but there was no association between any antihypertensive medications (i.e. betablockers, ACE inhibitors, angiotensin II receptor blockers, calcium channel blockers, thiazide diuretics) to psoriasis [23].

\section{Conclusion}

Our report summarized a possible furosemide-induced case of psoriasis among a 32-year-old African-American female with hypertension. Our case cannot be linked to other published reports or studies specifically with loop diuretics, but clinicians should be aware of drug-induced psoriasis. It is important to discontinue the suspected medication and provide symptomatic management, if there is either induction or exacerbation of psoriasis.

\section{References}

1. Menter A, Gottlieb A, Feldman SR, Van Voorhees AS, Leonardi CL, et al. (2008) Guidelines of care for the management of psoriasis and psoriatic arthritis: Section 1. Overview of psoriasis and guidelines of care for the treatment of psoriasis with biologics. J Am Acad Dermatol 58: 826-850.

2. Levine D, Gottlieb A (2009) Evaluation and management of psoriasis: an internist's guide. Med Clin North Am 93: 1291-1303.

3. Basavaraj KH, Ashok NM, Rashmi R, Praveen TK (2010) The role of drugs in the induction and/or exacerbation of psoriasis. Int J Dermatol 49:1351-1361.

4. Hook JB, Williamson HE (1965) Addition of the saluretic action of furosemide to the saluretic action of certain other agents. J Pharmacol Exp Ther 148: 
Citation: Clements J, Virga KG, Bickley AR. Possible Case Report of Furosemide-Induced Psoriasis. J Pharmaceu Pharmacol. $2015 ; 3(2)$ : 4.

\section{ISSN: $2327-204 X$}

88-93.

5. Prandota J, Witkowska M (1976) Pharmacokinetics and metabolism of furosemide in man. Eur J Drug Metab Pharmacokinet 1: 177-181.

6. Thestrup-Pedersen K (1987) Adverse reactions in the skin from antihypertensive drugs. Dan Med Bull 34 Suppl 1: 3-5.

7. Lee A (2005) Adverse drug reactions, 2nd edition. Pharmaceutical Press.

8. Naranjo CA, Busto U, Sellers EM, Sandor P, Ruiz I, et al. (1981) A method of estimating the probability of adverse drug reactions. Clin Pharmacol Ther 30: 239-245.

9. Ponka D (2006) Approach to managing patients with sulfa allergy: use of antibiotic and nonantibiotic sulfonamides. Can Fam Physician 52: 1434-1438.

10. Naisbitt DJ, Hough SJ, Gill HJ, Pirmohamed M, Kitteringham NR, et al. (1999) Cellular disposition of sulphamethoxazole and its metabolites: implications for hypersensitivity. Br J Pharmacol 126: 1393-1407.

11. Williams DP, Park BK (2003) Idiosyncratic toxicity: the role of toxicophores and bioactivation. Drug Discov Today 8: 1044-1050.

12. Schnyder B, Pichler WJ (2009) Mechanisms of drug-induced allergy. Mayo Clin Proc 84: 268-272.

13. Ponto LL, Schoenwald RD (1990) Furosemide (frusemide). A pharmacokinetic/ pharmacodynamic review (Part I). Clin Pharmacokinet 18: 381-408.

14. Ponto LL, Schoenwald RD (1990) Furosemide (frusemide). A pharmacokinetic/ pharmacodynamic review (Part II). Clin Pharmacokinet 18: 460-471.
15. Mitchell JR, Nelson WL, Potter WZ, Sasame HA, Jollow DJ (1976) Metabolic activation of furosemide to a chemically reactive, hepatotoxic metabolite. J Pharmacol Exp Ther 199: 41-52.

16. Williams DP, Antonie DJ, Butler PJ, Jones R, Randle L, et al. (2007) The metabolism and toxicity of furosemide in the Wistar rat and CD-1 mouse: a chemical and biochemical definition of the toxicophore. J Pharmacol Exp Ther 322: 1208-1220.

17. Peterson LA (2013) Reactive metabolites in the biotransformation of molecules containing a furan ring. Chem Res Toxicol 26: 6-25.

18. Thestrup-Pedersen K (1987) Adverse reactions in the skin from antihypertensive drugs. Dan Med Bull 34 Suppl 1: 3-5.

19. Noce R, Paredes BE, Pichler WJ, Krähenbühl S (2000) Acute generalized exanthematic pustulosis (AGEP) in a patient treated with furosemide. Am J Med Sci 320: 331-333.

20. Ochoa PS, Fisher T (2013) A 7-year case of furosemide-induced immune thrombocytopenia. Pharmacotherapy 33: e162-e165.

21. Maddox NI, Futral D, Boudreau FT (1992) Serologic investigation of fatal hemolytic anemia associated with a multiple drug history and Rh-like autoantibody. Immunohematology 8: 70-76.

22. Brauchli YB, Jick SS, Curtin F, Meier CR (2008) Association between betablockers, other antihypertensive drugs and psoriasis: population-based casecontrol study. Br J Dermatol 158: 1299-1307.

23. Wu S, Han J, Li WQ, Qureshi AA (2014) Hypertension, anti-hypertensive medication use, and risk of psoriasis. JAMA Dermatol 150: 957-963. 